\title{
Thermal Conductivity of Carbon/Carbon Composites with the Fiber/Matrix Interface Modified by Silicon Carbide Nanofibers
}

\author{
Jie Chen*, Xiang Xiong, Peng Xiao \\ State Key Laboratory of Powder Metallurgy, Central South University, Changsha, China \\ Email: *chenjiecsu@163.com
}

How to cite this paper: Chen, J., Xiong, $\mathrm{X}$. and Xiao, P. (2016) Thermal Conductivity of Carbon/Carbon Composites with the Fiber/ Matrix Interface Modified by Silicon Carbide Nanofibers. Advances in Chemical Engineering and Science, 6, 515-524. http://dx.doi.org/10.4236/aces.2016.64045

Received: September 29, 2016

Accepted: October 23, 2016

Published: October 26, 2016

Copyright $\odot 2016$ by authors and Scientific Research Publishing Inc. This work is licensed under the Creative Commons Attribution International License (CC BY 4.0). http://creativecommons.org/licenses/by/4.0/ (c) (i) Open Access

\begin{abstract}
Silicon carbide nanofibers grew on the surface of carbon fibers of a unidirectional carbon preform by CCVD and then chemical vapor infiltration was used to densify the preform to get the SiCNF-C/C composite. The effects of silicon carbide nanofibers on the microstructure of the pyrolytic carbon and the thermal conductivity of the SiCNF-C/C composite were investigated. Results show that silicon carbide nanofibers on the surface of carbon fibers induce the deposition of high texture pyrolytic carbon around them. The interface bonding between carbon fibers and pyrolytic carbon is well adjusted. So the efficiency of heat transfer in the interface of the composite is well enhanced. The thermal conductivity of the SiCNF-C/C composite is greater than that of the $\mathrm{C} / \mathrm{C}$ composite, especially the thermal conductivity perpendicular to the fiber axis.
\end{abstract}

\section{Keywords}

Silicon Carbide Nanofiber, Chemical Vapor Infiltration, Interface Bonding, Thermal Property

\section{Introduction}

Carbon/carbon (C/C) composite is a new-type of high-temperature material with lots of excellent performance, such as light weight, high modulus, high specific strength, low thermal expansion, high temperature resistance and outstanding corrosion resistance [1] [2]. C/C composites are widely used in aerospace industry and automobile industry. With the rapid development of science and technology, the electronic equipment of thermal control systems in aerospace crafts tends to miniaturization, lightweight, compaction and high-efficiency [3]. Therefore, heat dissipation gradually be- 
comes the key problem in the field of aerospace. There are large heat accumulations in aerospace equipment during operation, such as powerful electron apparatus and plasma facing components of fusion devices. For safe work of this equipment, the accumulated heat must be conducted away. So much attention has been paid on thermal properties of the materials [4] [5].

As we all know, the excellent thermal properties of $\mathrm{C} / \mathrm{C}$ composites are not only related to the performances of carbon fibers and matrix, but also dependent on the fiber/ matrix interface [6] [7]. A good fiber/matrix interface is beneficial to heat transfer, while a weak interface may impair the integrity of composites and become the thermal resistance. In recent years, many investigations have been carried out to modify the fiber/matrix interface to get high performance $\mathrm{C} / \mathrm{C}$ composites.

Carbon nanofibers (CNFs) are widely used in $\mathrm{C} / \mathrm{C}$ composites for interface modification due to their quasi-one-dimensional structure. After being modified by CNFs, the interface microstructure is adjusted and the properties of $\mathrm{C} / \mathrm{C}$ composites are enhanced [8] [9]. Silicon carbide nanofibers (SiCNFs) are the products of extreme anisotropic growth of SiC crystals. In addition to quasi-one-dimensional structure, SiCNF is the single crystalline component and has less structural defects [10] [11]. Therefore SiCNFs have high tensile strength, high resistance to corrosion and excellent oxidation resistance.

In this study, SiCNFs are prepared on the surface of carbon fibers by catalytic chemical vapor deposition (CCVD). The preform with SiCNFs was densified by chemical vapor deposition (CVI) to obtain SiCNF reinforced carbon/carbon (SiCNF-C/C) composites. The microstructure of fiber/matrix interface was deeply observed and analyzed. The thermal conductivity of the modified composites was investigated. The modification mechanism of SiCNFs was thoroughly discussed.

\section{Experimental}

\subsection{Preparation of Samples}

Unidirectional carbon preforms were made from T300 polyacrylonitrile-based (PAN) carbon fiber. Nickel particles used as catalysts were obtained on the fiber surface by electroplating, using $12 \mathrm{wt} \%$ nickel sulfate aselectrolyte. Electrolytic nickel plate was used as the anode and the unidirectional clothes were used as the cathode. The electronic current intensity was $10 \mathrm{~A}$. The electroplating time is $10 \mathrm{~min}$.

SiCNFs were then grown in situ on the fiber surface by CCVD. The CCVD process was performed at the temperature of $980^{\circ} \mathrm{C}$ under the pressure of $400 \mathrm{~Pa}$. Methyltrichorosilane (MTS) was used as the source of silicon carbide and hydrogen was used as carrier. Next, the SiCNFs-coated carbon clothes were stacked in the same direction to get the unidirectional carbon preform with fiber content of $31 \%$. CVI was applied to densify the unidirectional preform to obtain the modified composite (SiCNFs-C/C composite). For the purpose of comparison, a unidirectional $\mathrm{C} / \mathrm{C}$ composite with the same preform structure was prepared. Finally, the two composites were heated at $2300^{\circ} \mathrm{C}$. Composites with $0,2,4,6,8 \mathrm{wt} \%$ SiCNFs were fabricated (sample S0, S2, S4, 
S6, S8).

\subsection{Characterization}

The bulk density of the composites was measured by the Archimedes water immersion method analyzer at room temperature. The structure of SiCNFs was observed by transmission electron microscope (TEM). The surface structure of carbon fibers was examined using scanning electron microscope (SEM). The morphology and microstructure of $\mathrm{PyC}$ and fiber/matrix interface were studied by polarized light microscopy (PLM) and Raman spectroscopy. The fracture surface was analyzed by SEM.

The TC of composites was calculated by the formula:

$$
\lambda=418.68 a c_{p} d
$$

where $\lambda$ is TC $\left(\mathrm{W} \cdot \mathrm{m}^{-1} \cdot \mathrm{K}^{-1}\right), a$ is thermal diffusivity $\left(\mathrm{m}^{2} / \mathrm{s}\right), c_{p}$ is specific heat $(\mathrm{J} /(\mathrm{kg} \cdot \mathrm{K}))$ and $d$ is density of the composite $\left(\mathrm{g} / \mathrm{cm}^{3}\right)$. Thermal diffusivity, $a$, was measured by laser flash method on JR-1 type synthetical thermal tester. $c_{p}$ is the inherent property of materials and the $c_{p}$ of carbon materials at room temperature is $0.171 \mathrm{~J} /(\mathrm{kg} \cdot \mathrm{K})$. Where parallel TC refers to TC in the direction parallel to fiber axis and perpendicular TC refers to $\mathrm{TC}$ in the direction perpendicular to fiber axis, as shown in Figure 1.

\section{Results and Discussion}

\subsection{Effect of SiCNFs on the Microstructure of Composites}

Figure 2 shows the morphology and microstructure of SiCNF grown on the surface of carbon fibers. It can be seen from Figure 2(a) that a large amount of SiCNFs have grown on the surface of carbon fibers, uniform and densest. The SiCNFs become a lay of thick slipcover around the whole carbon fiber such as a good bridge between carbon fibers. TEM images (Figure 2(b)) further shows that the diameter of SiCNF is $20-30$
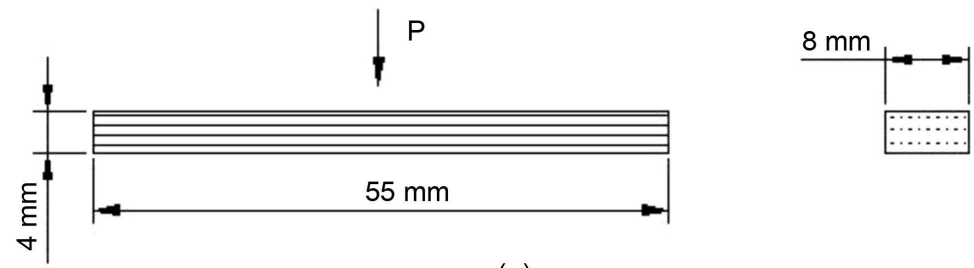

(a)
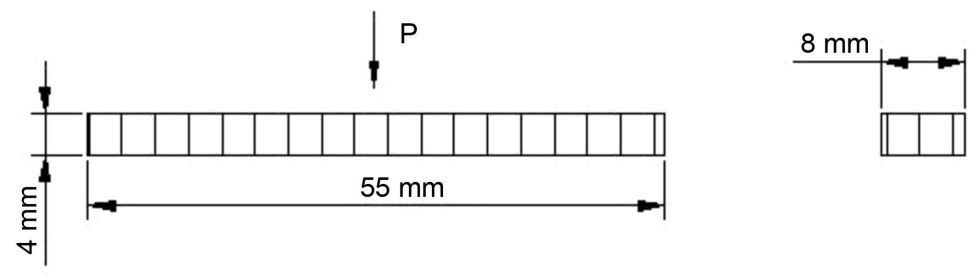

(b)

Figure 1. Sketch map of flexing intension test. (a) Vertical direction; (b) Parallel direction. 


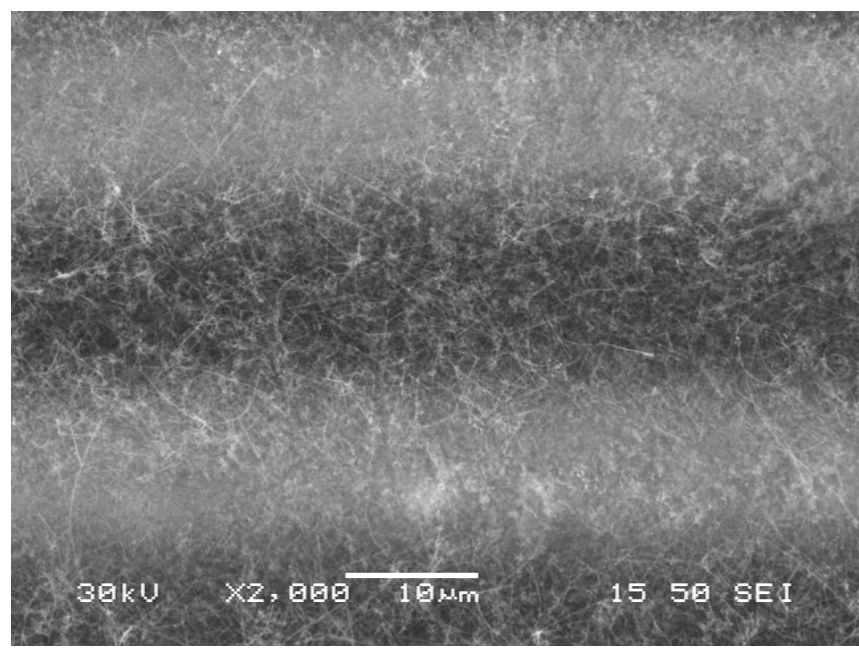

(a)

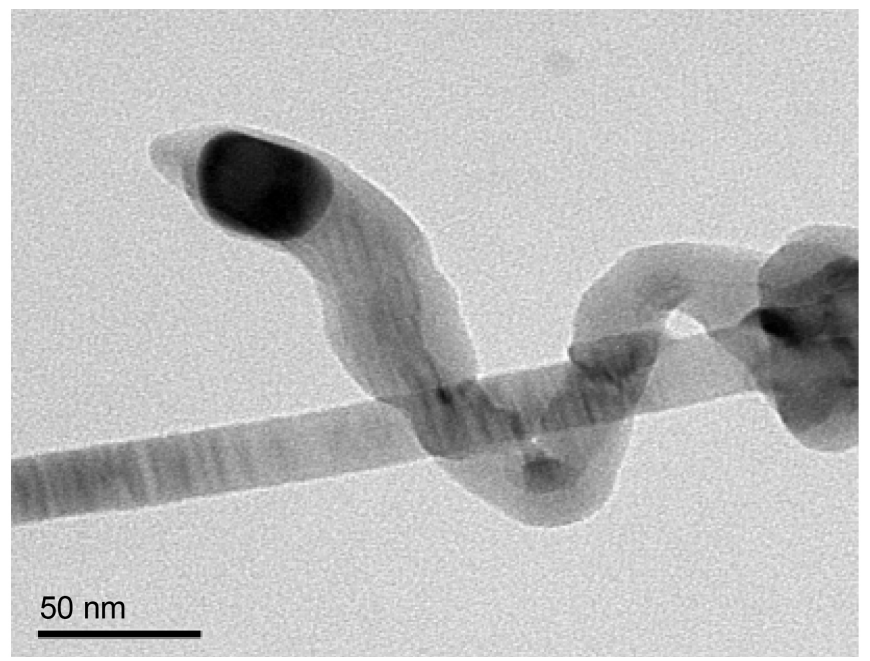

(b)

Figure 2. Morphology of in situ grown SiCNF.

$\mathrm{nm}$ and the length is $10-30 \mu \mathrm{m}$. The graphite lamellar of SiCNF arrange orderly, having high orientation.

The morphology of the C/C (S0) and SiCNFs-C/C composite (S4) viewed by SEM and polarized-light microscopy are shown in Figure 3 and Figure 4. For C/C composites, $\mathrm{PyC}$ around carbon fibers is in the shape of circular shell and has some homocentric annular cracks, which belongs to the typical smooth laminar (SL) PyC [12]. The interface between SL PyC and carbon fibers is loose with cracks, as shown in Figure 3(a). For SiCNFs-C/C composites, $\mathrm{PyC}$ deposited around carbon fibers is tiny particles, as shown in Figure 4(a). This layer of tiny particles is PyC with SiCNFs being wrapped inside. The $\mathrm{PyC}$ around carbon fibers has a strong optical reflectivity viewed by polarized-light microscopy, as in Figure 4(b). It can also be seen that hydrocarbon gases deposit around this layer of granular $\mathrm{PyC}$ with significant growth cone, as in Figure 4(b). 


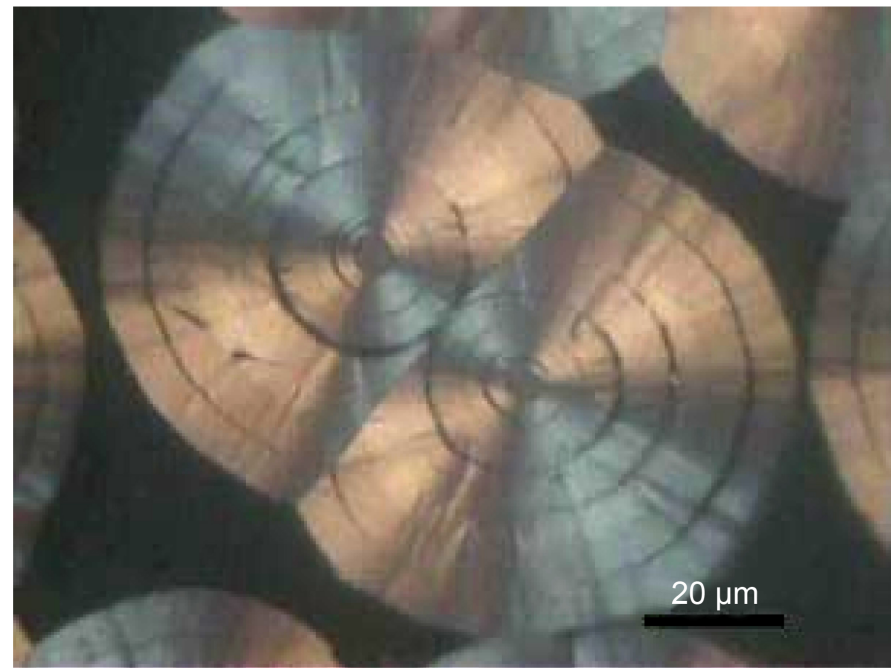

Figure 3. Optical photographs (under PLM) of C/C composites.

For further understanding of the microstructure of fiber/matrix interface, Raman spectra were also introduced. There are two main bands in Raman spectra of carbon materials. One is at about $1580 \mathrm{~cm}^{-1}$ (G band) corresponding to graphitic in-plane vibration with $\mathrm{E}_{2 \mathrm{~g}}$ symmetry and characterizing for the integrality of SP2 hybrid orbital structure. The other is at $1330 \mathrm{~cm}^{-1}$ (D band) corresponding to the defect lattice vibration. The reciprocal of $\mathrm{G}$ and $\mathrm{D}$ band intensity ratio, $1 / \mathrm{R}$, is proportional to graphitization degree [13] [14]. The detection points are collected from the skin region of fiber, fiber/PyC interface and $\mathrm{PyC}$, as shown in Figure 5.

Table 1 shows the 1/R values of two composites ( $\mathrm{S} 0$ and $\mathrm{S} 4$ ) at different locations. It can be seen that $1 / \mathrm{R}$ value of SiCNF-C/C composites is much higher than that of $\mathrm{C} / \mathrm{C}$ composites at corresponding locations. The $1 / \mathrm{R}$ value at location 1 of SiCNF-C/C composites is considerably higher than that of $\mathrm{C} / \mathrm{C}$ composites, as shown in Figure 6. Therefore the graphite crystallite of the granular interface layer of SiCNF-C/C composite is more integrated, compared with $\mathrm{C} / \mathrm{C}$ composite. Judging by PLM and Raman spectra, it is clear that SiCNFs grown on fiber surface lead to the deposition of the higher textured PyC during CVI process. So the interface between carbon fiber and PyC is tight and jagged in Figure 4.

\subsection{Effect of SiCNFs on TC of C/C Composites}

As we all known, the vibration of crystal lattices in carbon atoms is the base of heat conduction for $\mathrm{C} / \mathrm{C}$ composites. So the thermal conduction in $\mathrm{C} / \mathrm{C}$ composites may be regarded as the transfer of phonons in form of elastic waves. Namely, thermal conduction in $\mathrm{C} / \mathrm{C}$ composites is the result of interaction between phonons. According to Debby formula, TC of C/C composites can be expressed as follows [15]:

$$
\lambda=1 / 3 C \cdot v \cdot L
$$

where $L$ is mean-free path (the distance that phonons propagation between two scatterings), $C$ is specific heat and y is the lattice vibration velocity. It can be seen that TC 


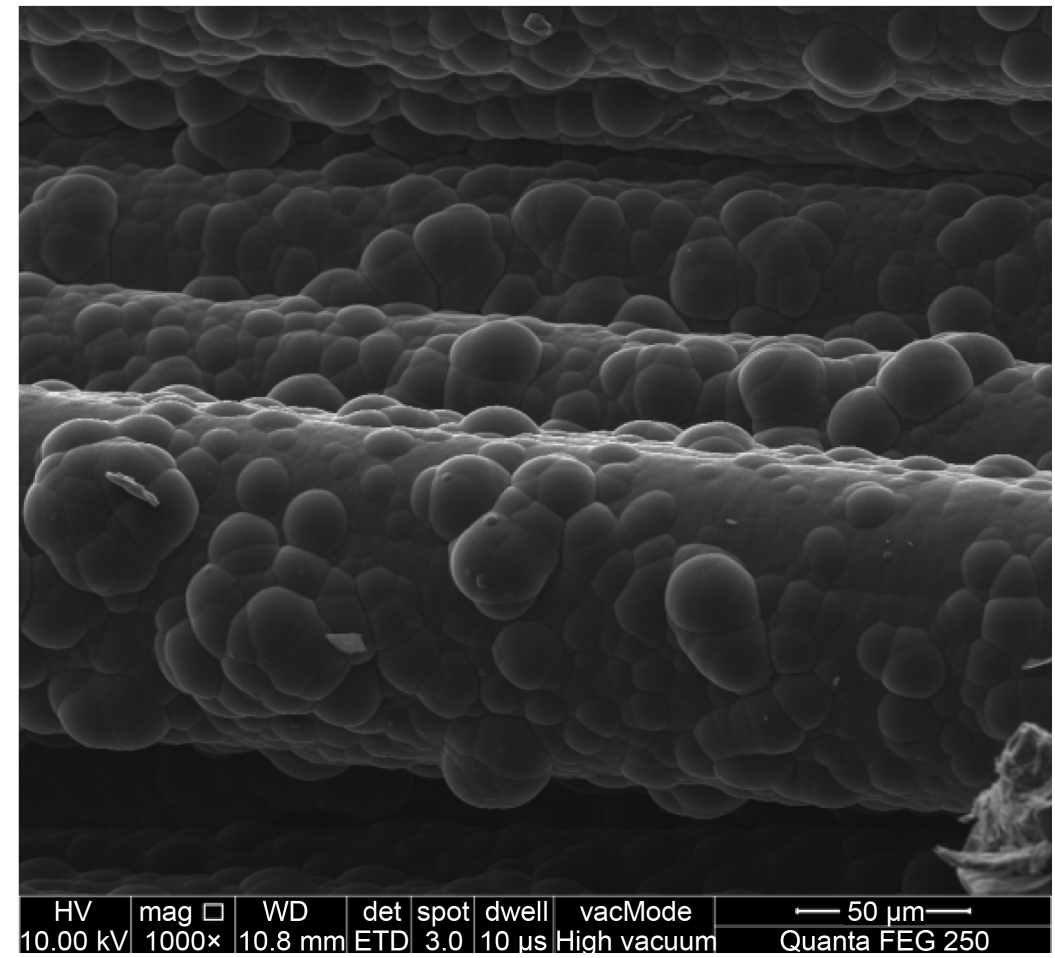

(a)

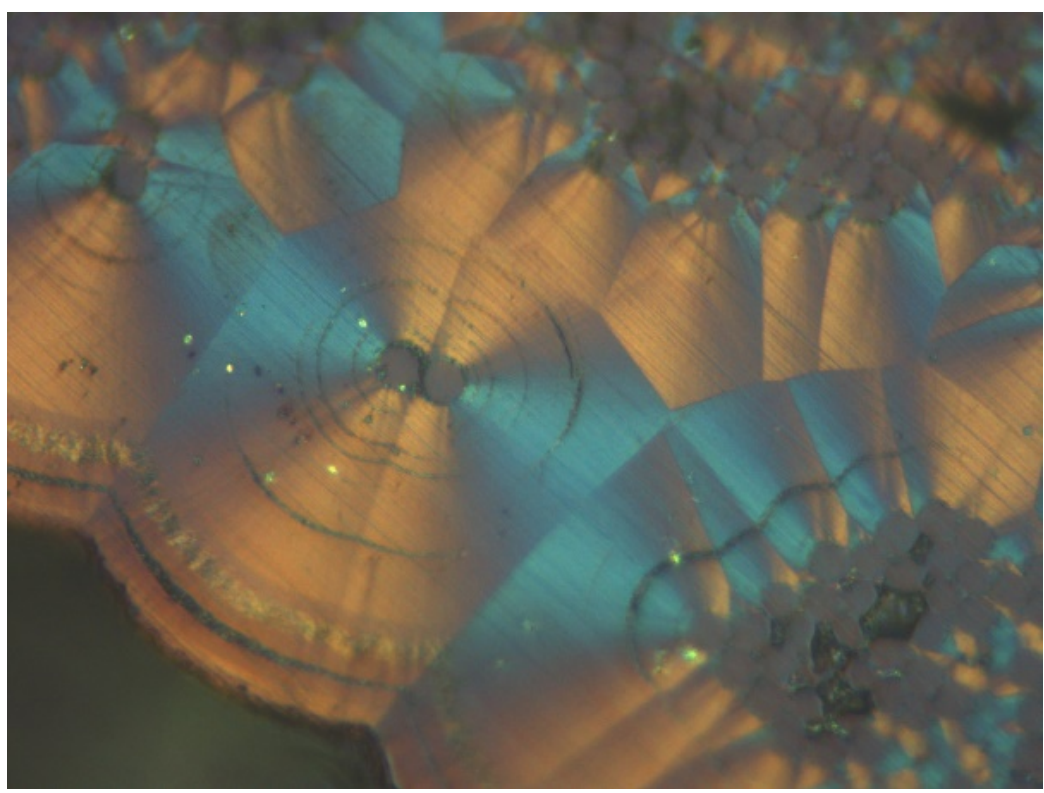

(b)

Figure 4. Morphology of SiCNF-C/C composites. (a) SEM image, (b)PLM image.

of carbon-graphite materials is mainly determined by the mean-free path. However, $L$ depends on the collision and scattering between phonons and it is proportional to the microcrystal size of material [16]. The working mode of phonons in C/C composites lies in: 1) phonon-phonon interaction, 2) phonon-imperfection or phonon-interface interaction. So the $\mathrm{TC}$ of the $\mathrm{C} / \mathrm{C}$ composite is closely related to carbon microstructures. 


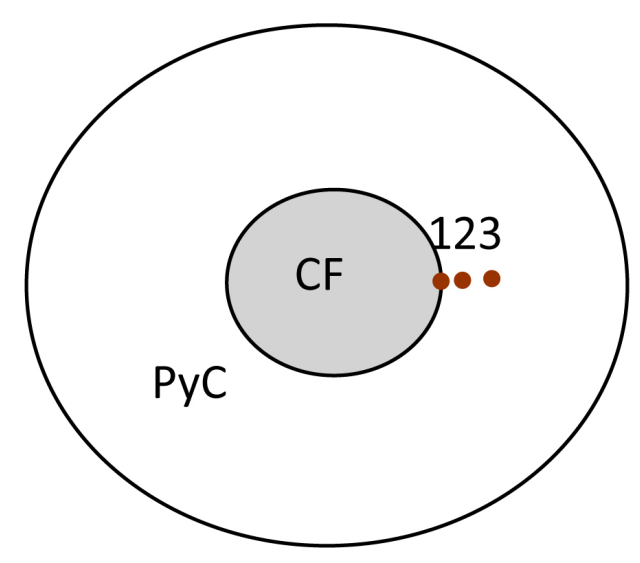

Figure 5. Schematic of Raman spectrum analysis.

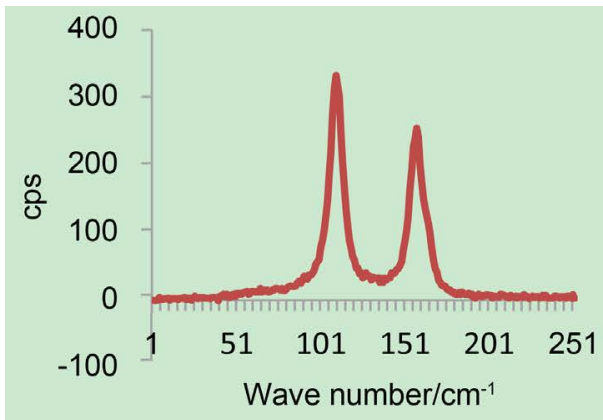

(a)

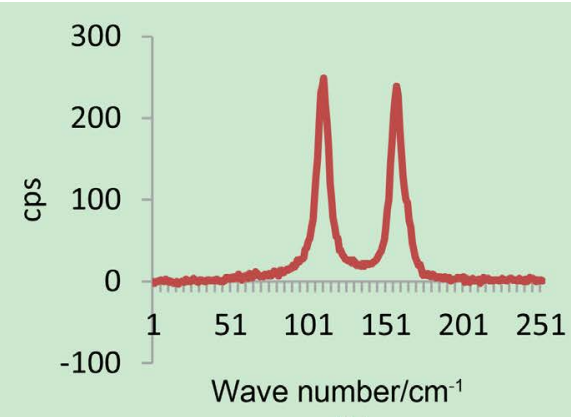

(b)

Figure 6. Raman spectra of PyC at location 1 in two composites. (a) C/C composite (S0); (b) SiCNFs-C/C composite (S4).

Table 1. 1/R value of corresponding PyC obtained from Raman spectra.

\begin{tabular}{ccccccc}
\hline Sample & \multicolumn{3}{c}{ C/C composite (S0) } & \multicolumn{3}{c}{ SiCNFs-C/C composite (S4) } \\
\hline Location & 1 & 2 & 3 & 1 & 2 & 3 \\
$1 / \mathrm{R}$ & 0.80 & 0.81 & 0.82 & 1.15 & 1.02 & 0.90 \\
\hline
\end{tabular}

Table 2 displays the properties of composites. Where parallel TC refers to TC in the direction parallel to fiber axis and perpendicular TC refers to TC in the direction perpendicular. The TC of SiCNF-C/C composites are all much higher than that of $\mathrm{C} / \mathrm{C}$ composite, one time higher in perpendicular TC and 15\% higher in parallel TC. When the content of SiCNFs exceeds $4 \%$, the graphitization degree of composites arises slightly with the increase of SiCNFs content. The TC of composites increases firstly and then decrease.

As for unidirectional $\mathrm{C} / \mathrm{C}$ composites, carbon fibers and carbon matrix are the main channels for heat conduction, in which carbon fibers are the dominating heat transfer channels in the direction along fiber axis and carbon matrix is the primary heat transfer channel in the direction perpendicular to fiber axis.

For parallel TC, the main pathways of thermal conduction are carbon fibers and the carbon matrix. As analyzed above, SiCNFs on carbon fibers induces ordered deposition 
Table 2. Properties of samples.

\begin{tabular}{|c|c|c|c|c|c|c|c|c|c|c|}
\hline & \multicolumn{2}{|r|}{ So } & \multicolumn{2}{|r|}{ S2 } & \multicolumn{2}{|c|}{ S4 } & \multicolumn{2}{|r|}{ S6 } & \multicolumn{2}{|c|}{ S8 } \\
\hline $\begin{array}{l}\text { SiCNFs content } \\
\quad(w t \%)\end{array}$ & \multicolumn{2}{|r|}{0} & \multicolumn{2}{|r|}{2} & \multicolumn{2}{|c|}{4} & \multicolumn{2}{|r|}{6} & \multicolumn{2}{|c|}{8} \\
\hline $\begin{array}{c}\text { Carbon volume } \\
\text { content }(\%)\end{array}$ & \multicolumn{2}{|c|}{31} & \multicolumn{2}{|r|}{31} & \multicolumn{2}{|c|}{31} & \multicolumn{2}{|r|}{31} & \multicolumn{2}{|c|}{31} \\
\hline $\begin{array}{l}\text { Densification } \\
\left(\mathrm{g} / \mathrm{cm}^{3}\right)\end{array}$ & \multicolumn{2}{|c|}{1.62} & \multicolumn{2}{|c|}{1.63} & \multicolumn{2}{|c|}{1.63} & \multicolumn{2}{|c|}{1.64} & \multicolumn{2}{|c|}{1.64} \\
\hline $\begin{array}{c}\text { Graphitization } \\
\text { degree }(\%)\end{array}$ & \multicolumn{2}{|r|}{55} & \multicolumn{2}{|r|}{65} & \multicolumn{2}{|c|}{67} & \multicolumn{2}{|r|}{70} & \multicolumn{2}{|c|}{66} \\
\hline Direction & $\perp$ & // & $\perp$ & $/ /$ & $\perp$ & // & $\perp$ & $/ /$ & $\perp$ & // \\
\hline $\mathrm{TC}\left(\mathrm{W} \cdot \mathrm{m}^{-1} \cdot \mathrm{K}^{-1}\right)$ & 12.4 & 110.6 & 20.5 & 155.2 & 25.4 & 168.4 & 27.8 & 182.2 & 23.07 & 164.8 \\
\hline
\end{tabular}

of $\mathrm{PyC}$ around them during CVI. PyC in SiCNF-C/C composites is similar to RL PyC. It has been analyzed that the $\mathrm{RL} \mathrm{PyC}$ in SiCNF-C/C composite has higher microcrystallite degree than that of SL PyC in C/C composite. After graphitization, the RL PyC has more complete microstructure with bigger $L c$ and less $\mathrm{d}_{002}$. That is to say, there are bigger $\mathrm{L}$ and few scattering centers for phonons vibration in SiCNF-C/C composites. So the parallel TC of SiCNF-C/C composite is higher than that of $\mathrm{C} / \mathrm{C}$ composite.

As for perpendicular TC, carbon matrix is the main heat transfer channel. Heat resistances mainly lie in matrix, such as interfacial cracks, pores and imperfections. Because the heat conduction in cracks mainly depends on the low heat diffusion of air in them, so the interfacial cracks, parallel to fiber axial, hinder the perpendicular heat transfer and reduce thermal conducting efficiency grievously in this direction. As analyzed above, SiCNFs on carbon fibers adjust the microstructure of fiber/matrix interface effectively. They lead to the deposition of the higher textured PyC around carbon fibers. So to speak, the interlayer distance of microcrystal $d_{002}$ decreases and the microcrystal size $L c, L a$ increases in the interface layer, compared with $\mathrm{C} / \mathrm{C}$ composite. The microstructure improvement of fiber/matrix interface leads to the increase of mean-free path in carbon matrix and the decrease of scattering centers at interface. So the efficiency of the thermal conduction in perpendicular direction is improved effectively. On the other hand, SiCNF is similar to CNF which is a kind of quasi-one-dimensional material. The phonon mean-free path in SiCNF is greatly increased and then thermal conduction is improved. So the SiCNFs growing vertical to carbon fibers is beneficial to perpendicular TC. Thus, the perpendicular TC of SiCNF-C/C composite is greatly higher than that of $\mathrm{C} / \mathrm{C}$ composites.

With the increases of SiCNFs content, the SiCNFs on carbon fibers will intertwined with each other. The entangled areas become the collision and scattering centers of phonons and reduce the efficiency of heat conduction of phonons. Therefore the TC of these composites increases firstly and then decreases, although the graphitization degree of SiCNF-C/C composites increases with the increasing of SiCNFs content. 


\section{Conclusion}

SiCNFs growing on the surface of carbon fibers are the nuclei for the deposition of ordered $\mathrm{PyC}$ around carbon fibers during CVI and then amend microstructure of fiber/ matrix interface. The high text $\mathrm{PyC}$ of fiber/matrix interface leads to the increase of phonon concentration and mean-free path, the decrease of scattering centers between phonon and interface. So the TC of composites is enhanced significantly, especially that along perpendicular direction.

\section{Acknowledgements}

This research work is supported by the National Natural Science Foundation of China No. 51505503 and by International S\&T Cooperation Program of China No. 2015DFR50580.

\section{References}

[1] Buckley, J.D. and Edie, D.D. (1993) Carbon-Carbon Materials and Composites. Noyes, Park Ridge, 1-14.

[2] Lu, S.L. and Rand, B. (2000) Large Diameter Carbon Filaments from Mesophase Pitch for Thermal Management Applications. New Carbon Materials, 15, 1-5.

[3] Chen, J., Xiong, X., Xiao, P. and Zhang, H.B. (2010) The Catalytic Effect of Boric Acid on Polyacrylonitrile-Based Carbon Fibers and the Thermal Conductivity of Carbon/Carbon Composites Produced from Them. Carbon, 48, 2341-2346. http://dx.doi.org/10.1016/j.carbon.2010.03.012

[4] Gao, L., Zhou, X.F. and Ding, Y.L. (2007) Effective Thermal and Electrical Conductivity of Carbon Nanotubes Composites. Carbon, 434, 297-300. http://dx.doi.org/10.1016/j.cplett.2006.12.036

[5] Luo, R.Y., Liu, T., Li, J.S., Zhang, H.B., Chen, Z.J. and Tian, G.L. (2004) Thermophysical Properties of Carbon/Carbon Composites and Physical Mechanism of Thermal Expansion and Thermal Conductivity. Carbon, 42, 2887-2895.

http://dx.doi.org/10.1016/j.carbon.2004.06.024

[6] Manocha, L.M., Warrier, A., Manocha, S. and Sathiyamoorthy, D. (2006) Thermophysical Properties of Densified Pitch Based Carbon/Carbon Materials-I. Unidirectional Composites. Carbon, 44, 480-487. http://dx.doi.org/10.1016/j.carbon.2005.08.012

[7] Gao, X.Q., Guo, Q.G., Liu, L. and Song, J.R. (2006) The Study Progress on Carbon Materials with High Thermal Conductivity. Journal of Functional Materials, 37, 173-177.

[8] Chen, J., Xiong, X. and Xiao, P. (2009) The Effect of Carbon Nanotube Growing on Carbon Fibers on the Microstructure of the Pyrolytic Carbon and the Thermal Conductivity of Carbon/Carbon Composites. Materials Chemistry and Physics, 116, 57-61. http://dx.doi.org/10.1016/j.matchemphys.2009.02.044

[9] Li, K.Z., Song, Q., Qiang, Q. and Ren, C. (2012) Improving the Oxidation Resisitance of Carbon/Carbon Composites at Low Temperature by Controlling the Grafting Morphology of Carbon Nanotubes on Carbon Fibers. Corrosion Science, 60, 314-317. http://dx.doi.org/10.1016/j.corsci.2012.03.031

[10] Xu, X.F., Xiao, P. and Xiong, X. (2009) The Control of Growth Velocity and Morphology of Catalytic Chemical Vapor Deposited SiC Nano-Fiber. Transactions of Nonferrous Metals Society of China, 19, 1146-1150. http://dx.doi.org/10.1016/S1003-6326(08)60420-3 
[11] Bahman, E., Tae, W.K., Muhammad, S. and Theodore, T.T. (2009) Effect of Polystyrene on the Morphology and Physical Properties of Silicon Carbide Nanofibers. Materials Chemistry and Physics, 118, 259-263. http://dx.doi.org/10.1016/j.matchemphys.2009.07.052

[12] Sun, W.C., Li, H.J., Han, H.M., Zhang, S.Y. and Li, K.Z. (2004) Microstructure of the Pyrocarbon Matrix Prepared by CLVI Process. Materials Science and Engineering, 369, 245-249. http://dx.doi.org/10.1016/j.msea.2003.11.025

[13] Jones, L.E. and Thrower, P.A. (1991) Influence of Boron on Carbon Fiber Microstructure, Physical Properties and Oxidation Behavior. Carbon, 29, 251-269. http://dx.doi.org/10.1016/0008-6223(91)90076-U

[14] Tuinstra, F. and Koenig, J.L. (1970) Raman Spectrum of Graphite. Journal of Chemical Physics, 53, 1126-1130. http://dx.doi.org/10.1063/1.1674108

[15] Guan, Z.D., Zhang, Z.T. and Jiao, J.S. (1992) Physical Performances of Inorganic Materials. Tsinghua University Press, Beijing, 131-150.

[16] Savage, G. (1993) Carbon Carbon Composites. Chapman \& Hall, London, 309-317. http://dx.doi.org/10.1007/978-94-011-1586-5

Submit or recommend next manuscript to SCIRP and we will provide best service for you:

Accepting pre-submission inquiries through Email, Facebook, LinkedIn, Twitter, etc.

A wide selection of journals (inclusive of 9 subjects, more than 200 journals)

Providing 24-hour high-quality service

User-friendly online submission system

Fair and swift peer-review system

Efficient typesetting and proofreading procedure

Display of the result of downloads and visits, as well as the number of cited articles

Maximum dissemination of your research work

Submit your manuscript at: http://papersubmission.scirp.org/

Or contact aces@scirp.org 